\title{
BMJ Open Prevalence and health correlates of reduced kidney function among community-dwelling Chinese older adults: the China Health and Retirement Longitudinal Study
}

\author{
Haiyu Jin, ${ }^{1}$ Jingyi Zhou, ${ }^{2}$ Chenkai Wu (D) ${ }^{1}$
}

To cite: Jin H, Zhou J, Wu C. Prevalence and health correlates of reduced kidney function among community-dwelling Chinese older adults: the China Health and Retirement Longitudinal Study. BMJ Open 2020;10:e042396. doi:10.1136/ bmjopen-2020-042396

- Additional material is published online only. To view please visit the journal online (http://dx.doi.org/10.1136/ bmjopen-2020-042396)

Received 03 July 2020 Revised 02 November 2020 Accepted 15 November 2020

D Check for updates

(C) Author(s) (or their employer(s)) 2020. Re-use permitted under CC BY-NC. No commercial re-use. See rights and permissions. Published by BMJ.

${ }^{1}$ Global Health Research Center, Duke Kunshan University, Kunshan, Jiangsu, China ${ }^{2}$ Kidney Disease Center, Zhejiang University School of Medicine First Affiliated Hospital, Hangzhou, Zhejiang, China

Correspondence to Dr Chenkai Wu; chenkai.wu@dukekunshan. edu.cn

\section{ABSTRACT}

Objectives We aimed to understand the prevalence of reduced kidney function in China by sociodemographics and geographical region, and to examine health correlates of reduced kidney function.

Design Cross-sectional study.

Setting and participants Participants were 6706 adults $\geq 60$ years from the 2015-2016 wave of the China Health and Retirement Longitudinal Study.

Outcome measures Reduced kidney function was defined as an estimated glomerular filtration rate of less than $60 \mathrm{~mL} / \mathrm{min}$ per $1.73 \mathrm{~m}^{2}$. The estimated glomerular filtration rate was calculated with the creatinine-cystatin C equation developed by the Chronic Kidney Disease Epidemiology Collaboration in 2012. The associations between reduced kidney function and potential risk factors were analysed using multivariable regression models. Results The prevalence of reduced kidney function was $10.3 \%$ (95\% Cl: $9.3 \%$ to $11.2 \%)$, corresponding to approximately 20 million older adults. Multivariable analysis showed that older adults with hypertension ( $\beta=-3.61,95 \% \mathrm{Cl}:-4.42$ to 2.79$)$, cardiac disease $(\beta=-1.90,95 \% \mathrm{Cl}:-2.93$ to 0.86$)$, who had a stroke ( $\beta=-3.75,95 \% \mathrm{Cl}:-6.35$ to 1.15$)$, kidney disease ( $\beta=-3.88,95 \% \mathrm{Cl}:-5.62$ to 2.13$)$, slow gait speed $(\beta=-2.23,95 \% \mathrm{Cl}:-3.27$ to 1.20$)$, and living in the South $(\beta=-4.38,95 \% \mathrm{Cl}:-5.95$ to 2.80$)$ and South Central ( $\beta=-1.85,95 \% \mathrm{Cl}:-3.15$ to 0.56 ) were more significantly likely to have reduced kidney function.

Conclusions Kidney function screening should be performed, especially in patients with hypertension, cardiac disease and who had a stroke. More efforts should be paid to improve the kidney function of older adults living in the South and South Central parts of China.

\section{INTRODUCTION}

Chronic kidney disease (CKD) has received increased attention due to its strong association with a variety of adverse outcomes, including cardiovascular disease and mortality. ${ }^{1-6}$ Globally, about 15.8 people died per 100000 population due to kidney diseases
Strengths and limitations of this study

- This study updated the prevalence of reduced kidney function among older Chinese people using a nationally representative sample.

- Instead of using traditional estimating equations based on serum creatinine alone, this study used an equation based on the combination of serum creatinine and serum cystatin $C$, potentially increasing the accuracy of the estimate.

- This study did not include albuminuria to identify reduced kidney function because this information was not available.

- Markers used to estimate glomerular filtration rate were measured only once.

- Much of the variation of estimated glomerular filtration rate is not explained by the factors considered in the present study.

in $2016,54.3 \%$ of which aged 70 years and older. $^{7}$

CKD is common in developing countries, including China, the world's most populous country with the largest number of older adults. ${ }^{8-10} \mathrm{~A}$ cross-sectional survey of a nationally representative sample of Chinese adults demonstrated that the overall prevalence of estimated glomerular filtration rate (eGFR), which is widely used to measure kidney function, ${ }^{11}$ less than $60 \mathrm{~mL} / \mathrm{min}$ per $1.73 \mathrm{~m}^{2}$ or the presence of albuminuria was $10.8 \%$ in 2009 $2010 .^{12}$ As the rapid age structure transition and socioeconomic development, ${ }^{13}$ which are well recognised to be associated with $\mathrm{CKD},{ }^{14}$ the prevalence of CKD in China might continue to change these years dramatically. However, the study on the prevalence of CKD using a nationwide representative population has not been updated for many years. Also, the measurements of eGFR in these studies 
Table 1 Characteristics of participants by kidney function

\begin{tabular}{|c|c|c|c|c|}
\hline & $\begin{array}{l}\text { Participants with eGFR } \\
<60 \mathrm{~mL} / \mathrm{min} \text { per } 1.73 \mathrm{~m}^{2} \\
(\mathrm{n}=630)\end{array}$ & $\begin{array}{l}\text { Participants with eGFR } \\
\geq 60 \mathrm{~mL} / \mathrm{min} \text { per } 1.73 \\
\mathrm{~m}^{2} \\
(\mathrm{n}=6076)\end{array}$ & $\begin{array}{l}\text { Overall } \\
(n=6706)\end{array}$ & \\
\hline & & & & $P$ value \\
\hline & & & Count $(c$ & \\
\hline Age (years) & & & & $<0.001$ \\
\hline $60-64$ & $80(11.7)$ & 2355 (38.6) & $2435(35.9)$ & \\
\hline $65-69$ & $119(16.0)$ & $1760(27.1)$ & $1879(25.9)$ & \\
\hline $70-74$ & $137(20.2)$ & $1081(18.0)$ & $1218(18.2)$ & \\
\hline $75-79$ & $146(26.2)$ & $574(10.5)$ & $720(12.1)$ & \\
\hline $80+$ & $148(25.9)$ & $306(5.8)$ & $454(7.9)$ & \\
\hline Male versus female & $299(46.0)$ & $3027(50.6)$ & $3326(50.1)$ & 0.260 \\
\hline Urban versus rural & 267 (48.2) & $2256(49.4)$ & $2523(49.3)$ & 0.010 \\
\hline Education & & & & $<0.001$ \\
\hline Illiterate* & $238(36.1)$ & $1766(25.2)$ & $2004(26.3)$ & \\
\hline Can read $\dagger$ & $180(27.9)$ & $1786(27.3)$ & $1966(27.3)$ & \\
\hline Elementary schoolł & $123(18.7)$ & $1379(23.3)$ & $1502(22.8)$ & \\
\hline Middle school§ & $57(9.5)$ & $779(14.1)$ & $836(13.6)$ & \\
\hline High school or above & $28(6.9)$ & $334(9.3)$ & $362(9.0)$ & \\
\hline Married versus others $\mathbb{\|}$ & $436(64.7)$ & $4909(80.2)$ & $5345(78.6)$ & $<0.001$ \\
\hline Body mass index $\left(\mathrm{kg} / \mathrm{m}^{2}\right)$ & & & & 0.005 \\
\hline$<18.5$ & $59(9.2)$ & $450(6.5)$ & $509(6.8)$ & \\
\hline $18.5-24.0$ & $281(44.4)$ & 3065 (48.6) & $3346(48.2)$ & \\
\hline $24.0-28.0$ & $177(27.0)$ & 1811 (32.3) & $1988(31.7)$ & \\
\hline$\geq 28$ & 87 (12.5) & 638 (10.9) & 725 (11.1) & \\
\hline
\end{tabular}

Percentage estimates were weighted using blood weight with household and individual response adjustment provided in the CHARLS. *No formal education or illiterate.

†Can read but did not finish elementary school.

łElementary school/traditional Chinese school.

§Including graduates from high school, vocational school, college or postgraduate.

IIncluding separated, divorced and never married.

CHARLS, China Health and Retirement Longitudinal Study; EGFR, estimated glomerular filtration rate.

were always based on serum creatinine alone, potentially leading to overestimates of CKD. ${ }^{15}$

In the present study, we used data from the China Health and Retirement Longitudinal Study (CHARLS), a nationally representative study of the communitydwelling Chinese population, to examine the prevalence of reduced kidney function among older adults by sociodemographics and geographical region. In addition, we examined health correlates of reduced kidney function and determined the prevalence of chronic conditions and geriatric syndromes by kidney function.

\section{METHODS}

\section{Cohort and participants}

We used data from the 2015-2016 wave of the CHARLS, a follow-up of an ongoing longitudinal survey of a nationally representative sample of community-dwelling adults aged $\geq 45$ years in China (we used older adults aged $\geq 60$ years). Participants were randomly chosen from 28 provinces and 450 villages and urban communities within these provinces, based on the probability-proportional-tosize random-sampling technique. ${ }^{16}$ CHARLS contacted local community hospitals or clinics to hire nurses to draw blood. Blood samples were shipped via cold chain to KingMed laboratory, a company that provides blood testing services to hospitals around China. Further details about the process of the blood sample collection, transportation and storage have been published elsewhere. ${ }^{17}$

In the 2015-2016 wave of CHARLS, a total of 21095 adults were interviewed and 20284 participants were asked to consent to a venous blood draw: 13013 (64.2\%) donated whole blood, ${ }^{17}$ of which 6743 participants were 60 years or older. The analytical sample consisted of 6706 adults who (1) were 60 years or older, (2) had complete data on creatinine and cystatin $\mathrm{C}$ (needed to estimate kidney function), and (3) had cross-sectional blood 


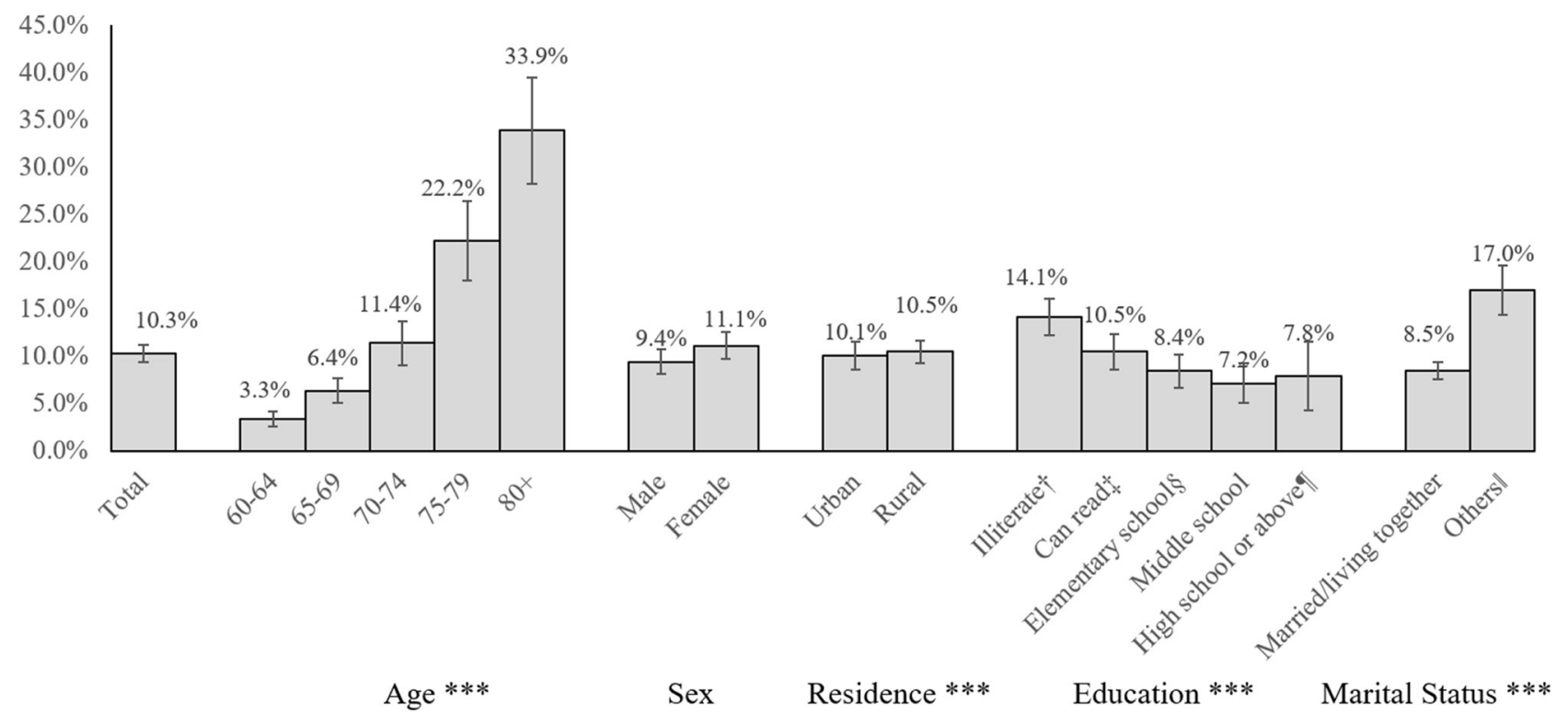

Figure 1 Prevalence of reduced kidney function (eGFR $<60 \mathrm{~mL} / \mathrm{min}$ per $1.73 \mathrm{~m}^{2}$ ). Prevalence estimates were weighted using blood weight with household and individual response adjustment provided in the CHARLS. $\mathrm{N}=12537$ for overall prevalence. Error bars $=95 \%$ Cls. ${ }^{\dagger}$ Illiterate: no formal education or illiterate. ${ }^{\ddagger}$ Can read: can read but did not finish elementary school. §Elementary school: elementary school/traditional Chinese school. "High school or above: including graduates from high school, vocational school, college or postgraduate. "Others: including separated, divorced and never married. ${ }^{\star \star \star} \mathrm{P}<0.001,{ }^{\star \star} \mathrm{p}<0.01$, ${ }^{*} \mathrm{p}<0.05$ for comparison. CHARLS, China Health and Retirement Longitudinal Study; eGFR, estimated glomerular filtration rate.

sample weight (online supplemental supporting information 1$).^{18}$

\section{Kidney function}

CKD is defined as abnormalities of kidney structure or function, present for 3 months, with implications for health; GFR is generally accepted as the best index of kidney function, and reduced kidney function is defined as a GFR less than $60 \mathrm{~mL} / \mathrm{min}$ per $1.73 \mathrm{~m}^{2}$, according to Kidney Disease Improving Global Outcomes guidelines. ${ }^{19}{ }^{20}$ The eGFR was calculated with the creatininecystatin $\mathrm{C}$ equation developed by the Chronic Kidney Disease Epidemiology Collaboration in 2012, which was better than equations based on creatinine or cystatin $\mathrm{C}$ alone $^{21}$ :

$135 \times \min \quad(\mathrm{Scr} / \mathrm{k}, \quad 1)^{\alpha} \times \max \quad(\mathrm{Scr} / \mathrm{k}, \quad 1)^{-0.601} \times \min$ $(\text { Scys } / 0.8,1)^{-0.375} \times \max (\text { Scys } / 0.8,1)^{-0.711} \times 0.995^{\text {Age }}(\times 0.969$ if woman), where Scr is serum creatinine $(\mathrm{mg} / \mathrm{dL})$, Scys is serum cystatin $\mathrm{C}(\mathrm{mg} / \mathrm{L}), \mathrm{k}$ is 0.7 for women and 0.9 for men, $\alpha$ is -0.248 for women and -0.207 for men, $\min$ indicates the minimum of Scr/k or 1, and max indicates the maximum of $\mathrm{Scr} / \mathrm{k}$ or 1 . Creatinine and cystatin $\mathrm{C}$ were examined at KingMed laboratory. Creatinine was measured by the picric acid method. Cystatin C was measured by immunoturbidimetric assay.

\section{Sociodemographics}

Sociodemographic characteristics included age (60-64, 65-69, 70-74, 75-79 and 80+ years), sex, education (no formal education/illiterate, can read but did not finish elementary school, elementary school/traditional Chinese school, middle school, and high school or above), marital status (married /living together vs others), current residence location (urban vs rural) and geographical region (Northwest, Northern, Central, Southwest, South, Northeast, East, South Central and Southeast).

\section{Health outcomes}

Self-reported diseases include hypertension, diabetes, cancer, cardiac disease (including myocardial infarction, coronary heart disease, angina, congestive heart failure and other heart problems), stroke, lung disease (including chronic lung diseases, such as chronic bronchitis and emphysema), liver disease (except fatty liver), kidney disease, stomach disease and arthritis. Depression was assessed by the modified Center for Epidemiologic Studies Depression Scale and a total score of $\geq 12$ was considered depressed. Falls in previous year were selfreported (yes or no). Participants who reported having difficulty in doing one or more activities of daily living (ADLs) tasks (dressing, bathing, eating, getting out of bed and toileting) or instrumental ADLs (IADLs) tasks (preparing hot meals, doing household chores, shopping, managing assets and taking medications) were considered having ADL or IADL disability. Participants who responded having difficulty performing any task of lower extremity function (getting up from a chair after sitting for a long period, climbing several flights of stairs without resting, stooping, kneeling and crouching) or upper extremity function (reaching or extending arms above shoulder level, lifting or carrying weights more than $5 \mathrm{~kg}$, and picking up a small coin from a table) were 


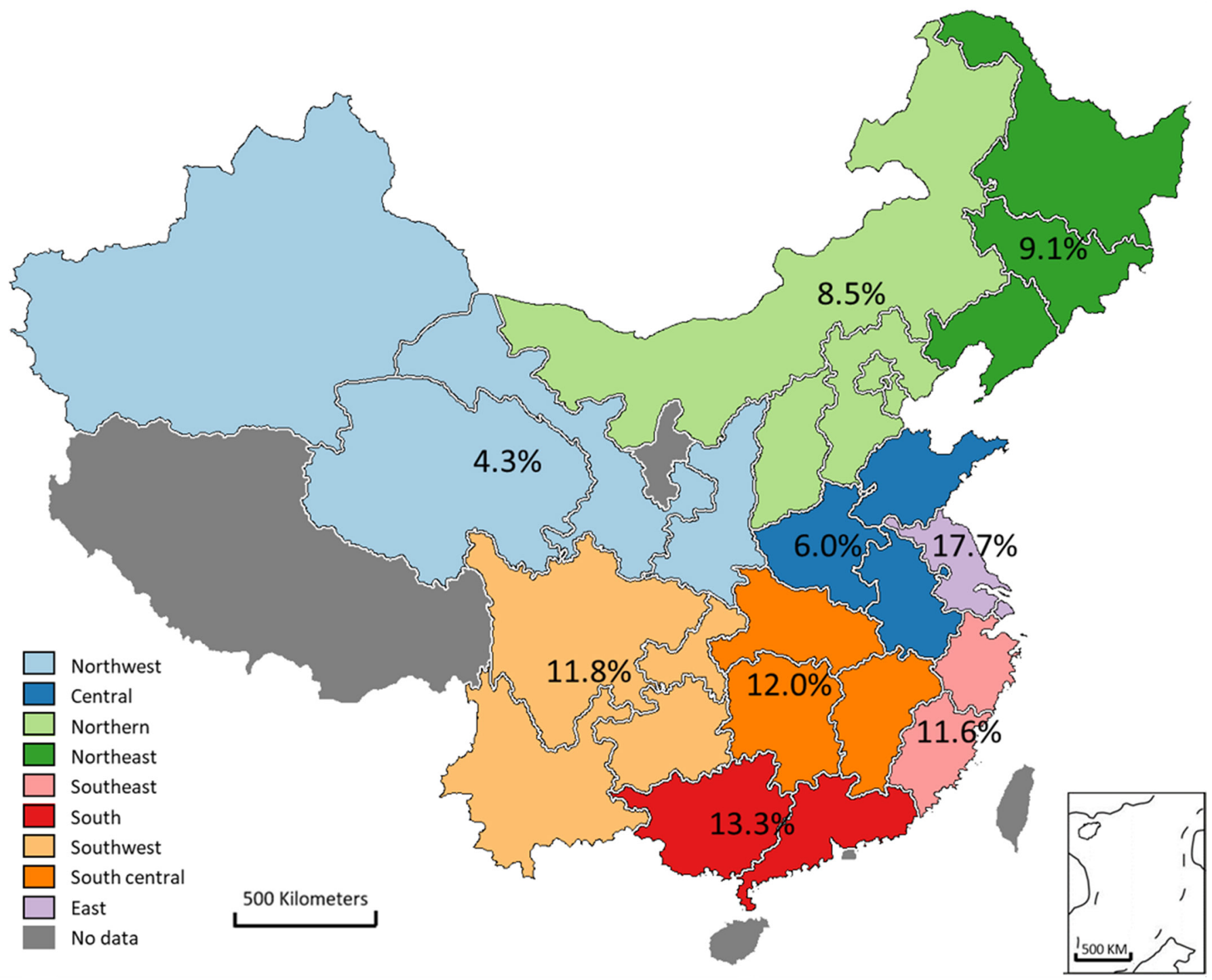

Figure 2 Prevalence of reduced kidney function (eGFR $<60 \mathrm{~mL} / \mathrm{min}$ per $1.73 \mathrm{~m}^{2}$ ) by districts. Prevalence was weighted using blood weight with household and individual response adjustment provided in the CHARLS. P<0.001. CHARLS, China Health and Retirement Longitudinal Study; eGFR, estimated glomerular filtration rate.

classified as having lower or upper extremity functional limitation. Gait speed was measured by the average of two-timed walk tests over a 2.5-metre course. We used the lowest quintile of the sample distribution as a cut-point to classify slow walkers $(<0.60 \mathrm{~m} / \mathrm{s})$ and non-slow walkers. Grip strength was defined as the maximum handgrip strength of either hand. Grip strength $<16 \mathrm{~kg}$ for women and $<26 \mathrm{~kg}$ for men was classified as 'weak'. ${ }^{22}$ Memory was self-rated (poor vs others).

\section{Statistical analysis}

Categorical variables were presented as proportions and tested by Chi-squared test for comparisons. All the prevalence, percentage and mean estimates were weighted to represent the population aged 60 years or older in China, using blood weight with household and individual response adjustment. Characteristics were described and stratified according to the presence of reduced kidney function (eGFR less than or higher than $60 \mathrm{~mL} / \mathrm{min}$ per $\left.1.73 \mathrm{~m}^{2}\right)$.

We estimated the prevalence of reduced kidney function by age, sex, residence, education, marital status, body mass index (BMI: $<18.5 \mathrm{~kg} / \mathrm{m}^{2}, 18.5-23.9 \mathrm{~kg} / \mathrm{m}^{2}, 24.0-$ $27.9 \mathrm{~kg} / \mathrm{m}^{2}$ and $\left.\geq 28.0 \mathrm{~kg} / \mathrm{m}^{2}\right)$ and geographical region.

We analysed the association between reduced kidney function (eGFR less than or higher than $60 \mathrm{~mL} / \mathrm{min}$ per $1.73 \mathrm{~m}^{2}$ ) and potential risk factors using multivariable regression models. We used the backward selection to select variables and included age, sex, residence, education, marital status, BMI, geographical regions, chronic conditions (hypertension, diabetes, cancer, cardiac disease, stroke, lung disease, liver disease, kidney disease, stomach disease, arthritis), geriatric syndromes (ADL disability, IADL disability, depression and poor self-rated memory) and functional ability (lower extremity functional limitation, upper extremity 
functional limitation and weak grip strength) in the initial model.

To examine the association of kidney function with chronic conditions, geriatric syndromes and functional ability, we reported the age-adjusted prevalence of chronic conditions (hypertension, diabetes, cancer, cardiac disease, stroke, lung disease, liver disease, kidney disease, stomach disease, arthritis and having $\geq$ two diseases), geriatric syndromes (falls in previous years, ADL disability, IADL disability, depression and poor self-rated memory) and functional ability (lower extremity functional limitation, upper extremity functional limitation, slow gait speed and weak grip strength) by kidney function.

All tests were two-sided with a significance level of $\mathrm{p}<0.05$. We performed all analyses using Stata V.15.0 (Stata Corp, College Station, Texas, USA).

We used the Strengthening the Reporting of Observational Studies in Epidemiology cross-sectional checklist when writing our report. ${ }^{23}$

\section{Patient and public involvement}

There were no participants involved in the development. The results of the survey are disseminated to the public through websites.

\section{RESULTS}

A total of 6706 adults aged 60 years or above were included. Participants with reduced kidney function (eGFR less than $60 \mathrm{~mL} / \mathrm{min}$ per $1.73 \mathrm{~m}^{2}$ ) were older and less educated, more likely to live in rural areas, and be not married than those with normal kidney function (table 1).

The prevalence of reduced kidney function was $10.3 \%$ (95\% CI: $9.3 \%$ to $11.2 \%$; figure 1 ). The prevalence of reduced kidney function increased with advancing age. Only $3.3 \%$ of persons aged 60-64 years had reduced kidney function, whereas $33.9 \%$ of those aged 80 years or older had reduced kidney function. We observed higher prevalence of reduced kidney function among persons with a lower level of education and who were not married. Slightly over $14.1 \%$ of participants having no formal education had reduced kidney function, whereas only $7.8 \%$ of persons with a high school or above education had reduced kidney function. The prevalence of reduced kidney function prevalence was two times higher among persons who were not married than married ones $(17.0 \%$ vs $8.5 \%$ ). No substantial sex or urban-rural difference was observed in the prevalence of reduced kidney function.

The prevalence of reduced kidney function varied greatly by geographical regions. The prevalence estimates ranged over fourfold from $4.3 \%$ in the Northwest to $17.7 \%$ in the East (figure 2). Regional disparities in the prevalence of reduced kidney function persisted after adjustment of age. The age-adjusted prevalence estimates ranged from $2.8 \%$ in the Northwest to $12.4 \%$ in the East (online supplemental supporting information 2). ${ }^{24}$
In the multivariable linear regression model, 10 variables that were significantly associated with kidney function were retained (table 2 ). The mean eGFR for persons aged $65-69,70-74,75-79$ and $80+$ years was $5.61,11.11$, 17.43 and $23.82 \mathrm{~mL} / \mathrm{min}$ per $1.73 \mathrm{~m}^{2}$ lower than the youngest group (60-64 years), respectively (table 2 ). We observed educational, rural-urban and regional differences in kidney function. Persons with BMI higher than $24 \mathrm{~kg} / \mathrm{m}^{2}$, chronic diseases (including hypertension, cardiac disease, stroke and kidney disease) and slow gait speed had lower eGFR than those without. The full model has a moderate correlation to reduced kidney function, and the $\mathrm{R}^{2}$ is 0.2473 .

Age-adjusted prevalence of chronic conditions (hypertension, stroke and kidney disease) was higher in persons with reduced kidney function than those without (table 3 ). The prevalence of comorbidity ( $\geq$ two conditions) was also significantly higher among persons with reduced kidney function $(58.1 \%)$ than those with normal kidney function $(46.5 \%)$. Compared with participants with normal kidney function, those with reduced kidney function had significantly higher age-adjusted prevalence of ADL disability (25.2\% vs $20.7 \%$ ) and IADL disability $(33.0 \%$ vs $24.0 \%)$. In addition, persons with reduced kidney function had higher rate of slow gait speed $(21.0 \%$ vs $16.2 \%$ ) than those with normal kidney function.

\section{DISCUSSION}

The primary purpose of this study was to understand the prevalence of reduced kidney function in China by sociodemographics and geographical region and to examine health correlates of reduced kidney function. In this nationally representative sample of community-dwelling Chinese adults aged 60 years and older, the prevalence of reduced kidney function was $10.3 \%$, corresponding to approximately 20 million older adults. Additionally, we showed that sociodemographics, geographical region, multimorbidity and disability were associated with reduced kidney function.

Although our results of the prevalence of reduced kidney function were not directly comparable with that of most previous studies because of the difference in eGFR estimation method and age range of participants, in line with previous investigations, we found that age, ${ }^{12} 25-27$ self-reported hypertension ${ }^{12} 252628$ and geographical region ${ }^{12} 26$ were most significant factors of reduced kidney function. In addition, consistent with previous studies from China, our study found that living in urban, less educated, not married, cardiac disease, stroke and kidney disease were associated with a higher prevalence of reduced kidney function. ${ }^{12}{ }^{26-28}$ It is worthwhile to mention that the association between BMI $\geq 28.0 \mathrm{~kg} / \mathrm{m}^{2}$ and reduced kidney function was of statistical and substantive significance, which was in line with previous studies suggesting overweight and obesity were significantly associated with baseline CKD and incident CKD. ${ }^{29}{ }^{30}$ The unadjusted prevalence of reduced kidney 
Table 2 Risk factors for eGFR (modelled continuously)

\begin{tabular}{|c|c|c|}
\hline & eGFR, $\mathrm{mL} / \mathrm{min}$ per $1.73 \mathrm{~m}$ & \\
\hline & $\beta(95 \% \mathrm{Cl})$ & $P$ value \\
\hline Age (years) & & \\
\hline $60-64$ & Ref. & Ref. \\
\hline $65-69$ & $-5.61(-6.53$ to -4.69$)$ & $<0.001$ \\
\hline $70-74$ & $-11.11(-12.20$ to -10.03$)$ & $<0.001$ \\
\hline $75-79$ & $-17.43(-18.79$ to -16.06$)$ & $<0.001$ \\
\hline $80+$ & $-23.82(-25.54$ to -22.09$)$ & $<0.001$ \\
\hline Urban versus rural & $-1.09(-1.89$ to -0.29$)$ & 0.007 \\
\hline High school education versus others & 1.74 (0.27 to 3.22$)$ & 0.021 \\
\hline Body mass index $\left(\mathrm{kg} / \mathrm{m}^{2}\right)$ & & \\
\hline$<24$ & Ref. & Ref. \\
\hline $24-28$ & $-1.95(-2.81$ to -1.09$)$ & $<0.001$ \\
\hline$\geq 28$ & $-3.61(-4.92$ to -2.30$)$ & $<0.001$ \\
\hline District & & \\
\hline East, Southwest or Southeast & Ref. & Ref. \\
\hline Northwest & 2.90 (1.43 to 4.37$)$ & $<0.001$ \\
\hline Northern & 3.34 (2.01 to 4.67$)$ & $<0.001$ \\
\hline South Central & $-1.85(-3.15$ to -0.56$)$ & 0.005 \\
\hline Central & 3.87 (2.84 to 4.90$)$ & $<0.001$ \\
\hline South & $-4.38(-5.95$ to -2.80$)$ & $<0.001$ \\
\hline Northeast & 2.24 (0.76 to 3.72$)$ & 0.003 \\
\hline Self-reported diseases & & \\
\hline Hypertension & $-3.61(-4.42$ to -2.79$)$ & $<0.001$ \\
\hline Cardiac disease & $-1.90(-2.93$ to -0.86$)$ & $<0.001$ \\
\hline Stroke & $-3.75(-6.35$ to -1.15$)$ & 0.005 \\
\hline Kidney disease & $-3.88(-5.62$ to -2.13$)$ & $<0.001$ \\
\hline Slow gait speed* & $-2.23(-3.27$ to -1.20$)$ & $<0.001$ \\
\hline Observations & 6273 & \\
\hline $\mathrm{R}^{2}$ & 0.2473 & \\
\hline
\end{tabular}

*We used the lowest quintile of the sample distribution as a cut-point to classify slow walkers $(<0.60 \mathrm{~m} / \mathrm{s})$ and non-slow walkers. eGFR, estimated glomerular filtration rate.

function varied widely across geographical regions. After adjustment for age, the prevalence declined in all regions except the Northeast, where the mean age was lowest (67.9 for the Northeast vs 68.6 for the nation), but regional disparities remained large, with more than four times the proportion of older adults with reduced kidney function in the East as in the Northwest. After multivariate adjustment, the East ceased to be the region with the highest prevalence of reduced kidney. Medical practices such as a more aggressive approach towards dialysis might explain the geographical variation as suggested by Couchoud et al. ${ }^{31}$ However, further studies are required to define causality. In line with previous studies, lower education levels were associated with lower kidney function. ${ }^{14}$ Better education could enable individuals to access better healthcare interventions, thus helping to improve kidney function. The results of this paper might support that hypertension, stroke and cardiac disease are risk factors for the development of CKD; however, the potential cause-effect associations could be in the opposite direction. Hypertension is widely known as one of the underlying causes of CKD, and it is possible that hypertension causes damage to the intrarenal vasculature, promoting intimal and medial thickening, renal ischaemia and glomerulosclerosis. ${ }^{32} 33$ Nevertheless, evidence also suggested that early kidney damage might precede the development of hypertension, leading to a vicious circle of kidney injury and hypertension. ${ }^{45}$ Stroke is both a cause and an effect of CKD: kidney disease may increase the risk of stroke, ${ }^{34}$ while drugs used to treat stroke such as mannitol might also cause kidney damage. ${ }^{6}$ Also, there are up to five complex interactions 
Table 3 Age-adjusted prevalence of chronic conditions, geriatric syndromes and functional ability by kidney function

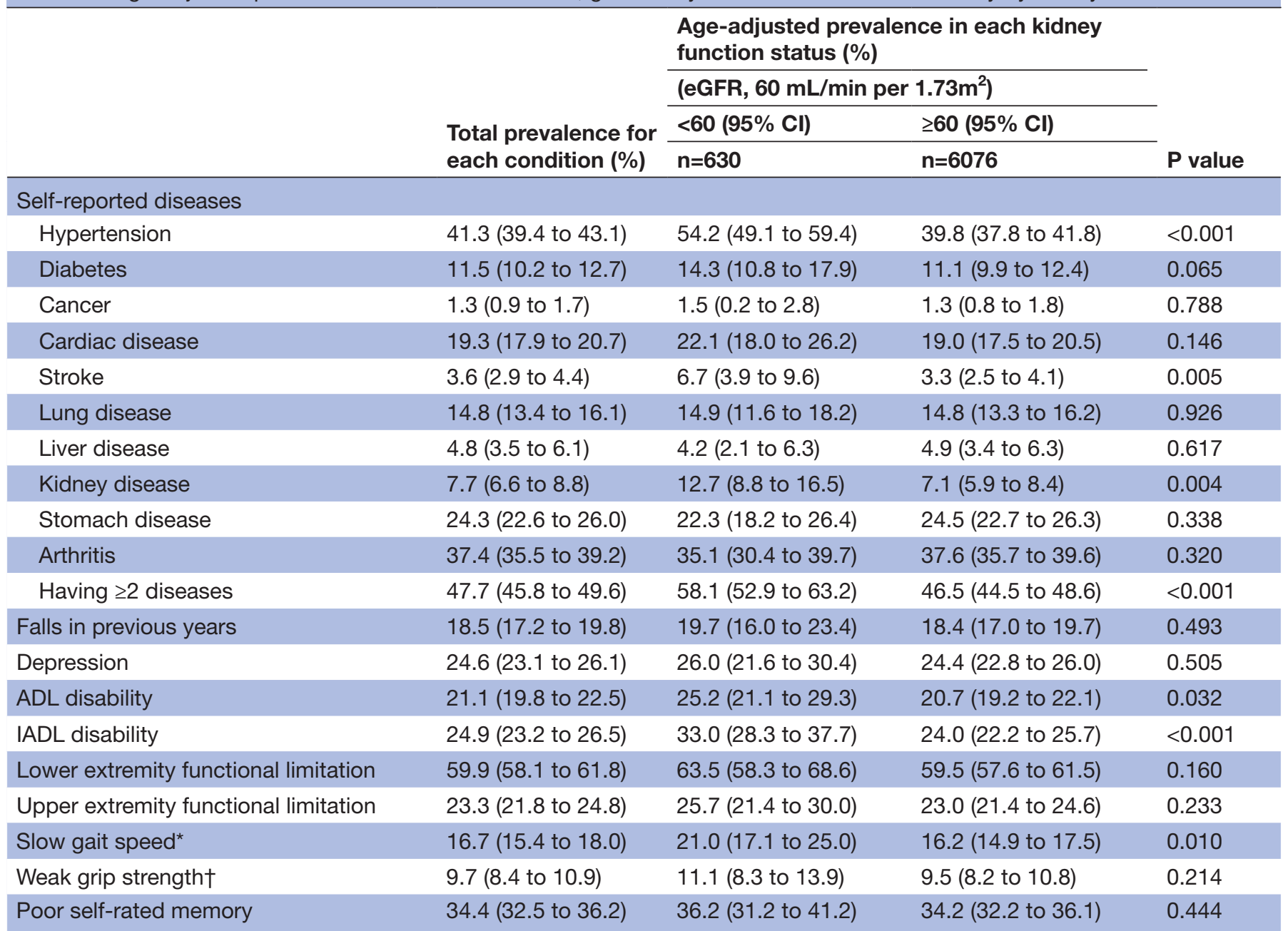

Prevalence and mean estimates were weighted using blood weight with household and individual response adjustment provided in the CHARLS. Age-adjusted prevalence was estimated at the overall median age (60 years).

*We used the lowest quintile of the sample distribution as a cut-point to classify slow walkers $(<0.60 \mathrm{~m} / \mathrm{s})$ and non-slow walkers.

†Grip strength was defined as the maximum handgrip strength of either hand. Grip strength $<16 \mathrm{~kg}$ for women and $<26 \mathrm{~kg}$ for men was classified as 'weak'.

ADL, activity of daily living; CHARLS, China Health and Retirement Longitudinal Study; eGFR, estimated glomerular filtration rate; IADL, instrumental ADL.

between the kidneys and the heart, which are known as the cardiorenal syndrome. ${ }^{3}$

Our study has several strengths. First, this study updated the prevalence of CKD among older Chinese people using a nationally representative sample. Second, instead of using traditional estimating equations based on serum creatinine alone, we used an equation based on the combination of serum creatinine and serum cystatin C, potentially increasing the accuracy of the estimate. Estimates of GFR (eGFR) with an equation based on serum creatinine level are routinely used because measuring the urinary clearance of exogenous markers such as inulin, a gold standard filtration marker, is not feasible in routine clinical practice. ${ }^{11}$ However, GFR estimates based on serum creatinine are imprecise, potentially resulting in overdiagnosis of $\mathrm{CKD}{ }^{15}$ To improve the precision, Inker et al developed an estimating equation based on the combination of serum creatinine and serum cystatin C in 2012, which was used in the present study, and found it more accurate than equations that used either marker alone, with $13.0 \%$ and $18.3 \%$ lower IQR for the bias than equations based on serum creatinine alone and serum cystatin $\mathrm{C}$ alone, respectively. ${ }^{21}$ We acknowledge several limitations. First, we did not include albuminuria to identify reduced kidney function because this information was not available. As a result, the actual prevalence of reduced kidney function in China is probably higher than reported here. We found that $10.3 \%$ of the older adults had reduced kidney function, but they might be healthy. We could not be confident about the real prevalence of CKD in the studied population without knowing what proportion of these $<60 \mathrm{~mL} / \mathrm{min} / 1.73 \mathrm{~m}^{2}$ subjects also had abnormal urine sediment or had albuminuria/ proteinuria. Furthermore, markers used to estimate GFR 
were measured only once. Finally, much of the variation of eGFR is not explained by the factors considered in the present study. Older adults are a highly heterogeneous group and variability in their health status is likely to be multidimensional. Future research is needed to identify novel risk factors for kidney function among this group.

The high prevalence of reduced kidney function indicated that CKD has become an important public health problem. Additionally, the substantial difference between geographical regions after multivariable adjustment suggested that more efforts should be paid to improve the kidney function of older adults living in the South and South Central parts of China. Moreover, given the fact that treatments are likely to be more effective if performed earlier in the conservative phase of $\mathrm{CKD}^{35}$ and the low awareness of CKD among older people in China, ${ }^{25}$ kidney function screening should be performed, especially in patients with hypertension, cardiac disease and who had a stroke.

Acknowledgements The authors are grateful to the China Health and Retirement Longitudinal Study (CHARLS) team for providing the data. The authors express great thanks to Xurui Jin for his technical support.

Contributors $\mathrm{HJ}$-analysis and interpretation of data and preparation of the manuscript. JZ—study concept and critical review. CW—study concept and design, and preparation and critical review of the manuscript. All authors have approved the final manuscript.

Funding This work was supported by Suzhou Municipal Science and Technology Bureau (SS2019069) and Chinese Ministry of Science and Technology (2020YFC2005600).

Map disclaimer The depiction of boundaries on this map does not imply the expression of any opinion whatsoever on the part of BMJ (or any member of its group) concerning the legal status of any country, territory, jurisdiction or area or of its authorities. This map is provided without any warranty of any kind, either express or implied.

Competing interests CW provides paid consultant services to HealthKeepers, a data analytics company in China.

Patient consent for publication Not required.

Ethics approval CHARLS was approved by the Ethical Review Committee of Peking University. Written informed consent was obtained from all study participants.

Provenance and peer review Not commissioned; externally peer reviewed.

Data availability statement Data are available in a public, open access repository. No data are available. All of the CHARLS data will be accessible to researchers around the world at the CHARLS website (http://charls.pku.edu.cn/en).

Supplemental material This content has been supplied by the author(s). It has not been vetted by BMJ Publishing Group Limited (BMJ) and may not have been peer-reviewed. Any opinions or recommendations discussed are solely those of the author(s) and are not endorsed by BMJ. BMJ disclaims all liability and responsibility arising from any reliance placed on the content. Where the content includes any translated material, BMJ does not warrant the accuracy and reliability of the translations (including but not limited to local regulations, clinical guidelines, terminology, drug names and drug dosages), and is not responsible for any error and/or omissions arising from translation and adaptation or otherwise.

Open access This is an open access article distributed in accordance with the Creative Commons Attribution Non Commercial (CC BY-NC 4.0) license, which permits others to distribute, remix, adapt, build upon this work non-commercially, and license their derivative works on different terms, provided the original work is properly cited, appropriate credit is given, any changes made indicated, and the use is non-commercial. See: http://creativecommons.org/licenses/by-nc/4.0/.

\section{ORCID iD}

Chenkai Wu http://orcid.org/0000-0002-0072-694X

\section{REFERENCES}

1 Vanholder R, Massy Z, Argiles A, et al. Chronic kidney disease as cause of cardiovascular morbidity and mortality. Nephrol Dial Transplant 2005;20:1048-56.

2 , Matsushita K, van der Velde M, et al, Chronic Kidney Disease Prognosis Consortium. Association of estimated glomerular filtration rate and albuminuria with all-cause and cardiovascular mortality in general population cohorts: a collaborative meta-analysis. Lancet 2010;375:2073-81.

3 Gansevoort RT, Correa-Rotter R, Hemmelgarn BR, et al. Chronic kidney disease and cardiovascular risk: epidemiology, mechanisms, and prevention. Lancet 2013;382:339-52.

4 Brantsma AH, Bakker SJL, de Zeeuw D, et al. Urinary albumin excretion as a predictor of the development of hypertension in the general population. J Am Soc Nephrol 2006;17:331-5.

5 Kestenbaum B, Rudser KD, de Boer IH, et al. Differences in kidney function and incident hypertension: the multi-ethnic study of atherosclerosis. Ann Intern Med 2008;148:501-8.

6 Hsieh $\mathrm{C}-\mathrm{Y}$, Lin $\mathrm{H}-\mathrm{J}$, Chen $\mathrm{C}-\mathrm{H}$, et al. Chronic kidney disease and stroke. Lancet Neurol 2014;13:1071.

7 World Health Organization. Projections of mortality and causes of death. 2016 to 2020;2060 https://www.who.int/healthinfo/global_ burden_disease/projections/en/

8 Wang J, Zhang L, Tang SC-W, et al. Disease burden and challenges of chronic kidney disease in North and East Asia. Kidney Int 2018;94:22-5.

9 Huang Y-M, Xu D, Long J, et al. Spectrum of chronic kidney disease in China: a national study based on hospitalized patients from 2010 to 2015. Nephrology 2019;24:725-36.

10 Zhang Q-L, Rothenbacher D. Prevalence of chronic kidney disease in population-based studies: systematic review. BMC Public Health 2008;8:1-13.

11 Stevens LA, Levey AS. Measurement of kidney function. Med Clin North Am 2005;89:457-73.

12 Zhang L, Wang F, Wang L, et al. Prevalence of chronic kidney disease in China: a cross-sectional survey. Lancet 2012;379:815-22.

13 United Nations and Affairs DoEaS. World population prospects: the 2019 revision, 2019. Available: https://www.un.org/en/development/ desa/population/theme/trends/index.asp

14 Zeng X, Liu J, Tao S, et al. Associations between socioeconomic status and chronic kidney disease: a meta-analysis. J Epidemiol Community Health 2018;72:270-9.

15 Stevens LA, Coresh J, Greene T, et al. Assessing kidney function-measured and estimated glomerular filtration rate. $N$ Engl J Med 2006;354:2473-83

16 Zhao Y, Hu Y, Smith JP, et al. Cohort profile: the China health and retirement longitudinal study (CHARLS). Int J Epidemiol 2014;43:61-8.

17 Chen X, Crimmins E, Hu PP, et al. Venous blood-based biomarkers in the China health and retirement longitudinal study: rationale, design, and results from the 2015 wave. Am J Epidemiol 2019;188:1871-7.

18 Supporting Information 1. Flow chart of the study populations in the 2015-2016 wave of the China health and retirement longitudinal study.

19 KDIGO. KDIGO 2012 clinical practice guideline for the evaluation and management of chronic kidney disease. Kidney International Supplements 2013:1-150.

20 Levey AS, Eckardt K-U, Tsukamoto Y, et al. Definition and classification of chronic kidney disease: a position statement from kidney disease: improving global outcomes (KDIGO). Kidney Int 2005;67:2089-100

21 Inker LA, Schmid CH, Tighiouart $\mathrm{H}$, et al. Estimating glomerular filtration rate from serum creatinine and cystatin C. N Engl J Med 2012;367:20-9.

22 Alley DE, Shardell MD, Peters KW, et al. Grip strength cutpoints for the identification of clinically relevant weakness. J Gerontol A Biol Sci Med Sci 2014;69:559-66.

23 E AD E, Egger M, Pocock SJ, et al. The strengthening the reporting of observational studies in epidemiology (STROBE) statement: guidelines for reporting observational studies.

24 Supporting Information 2. Age-Adjusted prevalence (\%) of reduced kidney function by region.

25 Wang S, Chen R, Liu Q, et al. Awareness and treatment of chronic kidney disease among middle-aged and elderly: the China health and retirement longitudinal study: prevalence and treatment of CKD in China. Nephrology 2015;20:474-84.

26 Du Y, Zhang S, Hu M, et al. Prevalence of chronic kidney disease markers: evidence from a three-million married population with fertility desire in rural China. Sci Rep 2017;7:2710-9. 
27 Chen J, Wildman RP, Gu D, et al. Prevalence of decreased kidney function in Chinese adults aged 35 to 74 years. Kidney Int 2005;68:2837-45.

28 Liu Z, Huang J, Qian D, et al. Prevalence and related factors of chronic kidney disease (CKD) among long-lived individuals (LLI) over 95 years of age. Arch Gerontol Geriatr 2015;60:354-8.

29 Kramer H, Luke A, Bidani A, et al. Obesity and prevalent and incident CKD: the hypertension detection and follow-up program. Am J Kidney Dis 2005;46:587-94.

30 Gelber RP, Kurth T, Kausz AT, et al. Association between body mass index and CKD in apparently healthy men. Am J Kidney Dis 2005;46:871-80.

31 Couchoud C, Guihenneuc C, Bayer F, et al. Medical practice patterns and socio-economic factors may explain geographical variation of end-stage renal disease incidence. Nephrol Dial Transplant 2012;27:2312-22.

32 Harvey JM, Howie AJ, Lee SJ, et al. Renal biopsy findings in hypertensive patients with proteinuria. Lancet 1992;340:1435-6.

33 Whelton PK, Klag MJ. Hypertension as a risk factor for renal disease. review of clinical and epidemiological evidence. Hypertension 1989;13:I19-I-27.

34 Toyoda K, Ninomiya T. Stroke and cerebrovascular diseases in patients with chronic kidney disease. Lancet Neurol 2014:13:823-33.

35 Locatelli F, Vecchio LD, Pozzoni P. The importance of early detection of chronic kidney disease. Nephrol Dial Transplant 2002;17 Suppl $11: 2-7$. 